\title{
Strategy and Tactics of Bank Capital Assessment
}

\author{
Submitted 29/08/19, 1st revision 21/09/19, 2nd revision 25/10/19, accepted 13/12/19
}

\section{Posnaya, E.A. ${ }^{1}$, Vorobyova, I.G. ${ }^{2}$, Ditsulenko O.I. ${ }^{3}$, Kaznova, M.I. ${ }^{4}$}

\begin{abstract}
:
Purpose: The article deals with the the development of strategic and tactical measures aimed at an effective estimate of banking institutions' capital volume by using a selective model. The result of evaluation from the capital factor is important for banking institutions, because it allows to determine more qualitatively the risk of bankruptcy.

Design/Methodology/Approach: Strategies and tactics developed by evaluation using a selective model are important for a qualitative assessment of the banking institutions' capital. The strategic direction of research for the purpose of monitoring the implementation of the program by the Central Bank for the commercial banks is to offer selective model that contains the ratio of liquidity, risk, relative and absolute levels of equity, the reliability of the bank and the extent of the bank information technology equipment.

Findings: A link reliability values of parameters of the banking institutions with the calculated values of the bank capital factor, namely the banks analyzed by the criterion of the probability of bankruptcy and situational correction bank financial policy is found to carry out an accurate assessment of the bank capital.

Practical Implications: The results can be incorporated into the activities of banking institutions with the aim of strengthening the position of financial stability and the reliability of the bank institution.

Originality/Value: The main contribution of this study is that the timely action taken as a result of the settlement of the developed selective model will reduce the number of bankruptcies which will have a positive impact on the economy in general and on the functioning of the banking institutions in particular.
\end{abstract}

Keywords: Bank capital, reliability, capital factor, bankruptcy risk, strategy, tactics.

JEL Codes: F60, F63, O35, O44.

Paper Type: Research article dedicated to Russian Economy.

${ }^{1}$ Candidate of Science (Economics), Associate Professor of the Department of "Finance", Sevastopol State University, Sevastopol, sntulena@mail.ru

${ }^{2}$ Candidate of Science (Economics), Associate Professor of the Department of "Banking", Rostov State University of Economics, Rostov-on-Don, iv.pochta@mail.ru

${ }^{3}$ Postgraduate of the Department of "Finance", Sevastopol State University, Sevastopol, info-erk@yandex.ru

${ }^{4}$ Candidate of Science (Economics), Associate Professor of the Department of "Finance", Sevastopol State University, Sevastopol, $\underline{\text { m-kaznova@mail.ru }}$ 


\section{Introduction}

As it has been studied and described previously (Posnaya et al., 2017), the mechanism for the implementation of capital improvement of the system of banking institutions should include financial strategy and financial stability. This research has been conducted on the example of the Russian Federation. The strategy basically should include long-term actions and tactics that are daily activities at usual level values.

The given strategy (Raisberg et al., 2005) is the conceptual basis of the bank activities of the institution, defining its main goals, objectives and ways of implementation. Strategy of the capital management system is a set of measures to achieve the main goal a quality assessment of bank capital for early definition of existing and potential problems, strengths and weaknesses of the banking institution, which directly impact on the basic purpose of banking activities - maximizing profit level (Rupeika-Apoga et al., 2018). The strategy to improve evaluation of bank capital is one of the functions of management, which is the implementation of an innovative method of estimating the capital (Kryksin, 2005). In this study, the mechanism of the strategic estimate of the banking institution capital is a selective model that by grouping characteristics for cost-effective path to the Central Bank of the Russian Federation will help to identify problem banking institutions on the criterion of lack of capital for the effective functioning of the bank or the capital incorrect use (Bortnikov, 2007).

\section{Theoretical, Empirical and Methodological Grounds of the Research}

Mechanism for implementing the system improvement capital assessment of the banking institution is a tool for organizing the effective implementation of programmatic activities and monitor the achievement of outcomes fulfillment. Selective model that contains the coefficients of liquidity, risk, relative and absolute levels of equity, the reliability of the bank, the extent of the bank information technology equipment was offered for the purpose of monitoring the implementation of the program by the Russia's Central Bank of commercial banks (Posnaya et al., 2018a). The inclusion in the model data of liquidity is defined by obtaining the regulator information to ensure timely and full execution of the establishment of the bank own obligations (Mahboud, 2017). Calculations of this group will prevent a lack of liquidity. Risks, their calculation and management focus at monitoring, analysis, coordination, determination of the degree of compliance (Posnaya et al., 2018b). Risk management system must be continuously reviewed and improved considering changing situation in the banking market (Milenkov, 2005; Sharifz et al., 2018).

Value accounting model, the relative and absolute levels of equity capital is an important point, because the relative index that allow to draw conclusions about the effectiveness of the banking institution. But the absolute level of performance demonstrates several important areas of focus: the value (scale) of the bank, the 
amount of operating the bank equity, income and expenses of the bank institutions that must necessarily be taken into account in the assessment of the bank capital.

Reliability parameters demonstrate the level of customer trust banking institutions. Reliability is a rather subjective factor. Some customers rely on the assessments of rating agencies, customer reviews and folk reliability ratings. The Sberbank of Russia PJSC, which is in the first place ranking of Russian most reliable banks, not only in terms of equity, but also on the amount of assets, as well as on the level of individual deposits is an example of the degree of reliability. The VTB Bank PJSC, one of the largest and most reliable banks in Russia is in the second place on the grounds of reliability. The Gazprombank JSC as one of the most reliable banks in Russia on the third place in terms of reliability. It was created in order to finance infrastructure projects in the oil and gas industry (Tachmatzidi, 2019).

The Russian Agricultural Bank JSC, which was created to encourage the development of agriculture in the Russian Federation takes the fourth place in terms of reliability. At present, the bank offers a wide range of services not only for agriculture but also for all the sectors of the economy. The Alfa-Bank JSC, which is one of the largest private banks in the Russian Federation has the fifth position in terms of reliability. International rating agencies assigned Alfa-Bank JSC with high reliability rating. The Credit Bank of Moscow PJSC, which runs on the Russian banking services market since 1992 takes the sixth place according to criterion of reliability. It provides a full range of services for corporate clients and individuals. Territorial network of the Bank has over 90 offices in Moscow and in the Moscow region.

The Bank FC Otkritie PJSC is on the seventh position. Bank Otkritie Financial Corporation was founded in 1993, it is the parent company of the banking group FC Otkritie. The UniCredit Bank JSC has the eighth place in terms of reliability. It is a commercial bank operating in the Russian Federation since 1989. At present, it is a representative of a European banking group UniCredit in Russia. The Raiffeisen Bank JSC which operates in the Russian Federation since 1996 is on the ninth position. It is a subsidiary of Raiffeisen Bank International which provides a full range of services to private clients, corporate, residents, non-residents, in rubles and foreign currency.

The Rosbank PJSC, which is part of the international financial group Societe Generale takes the tenth place on the criterion of reliability. The headquarters is in Moscow. Rosbank PJSC clients are more than three million individuals and one hundred thousand corporate clients. The last group of model selective characteristics is the application of information technology which allow assessing bank capital using innovative approaches and methods; it will have a significant impact on the quality of the assessment and the efficiency of the bank capital.

Let's make an estimate investigation of banking capital according to appropriate calculations K0 bank capital factor. The purpose of the payment is to determine whether the given rating of reliability on the submitted items is equivalent to the rate 
of bankruptcy probability. The compact form factor of the capital represented in the form (Posnaya et al., 2018b) as follows:

$$
\mathrm{K}_{0}=\sum_{\mathrm{i}=1}^{14} \mathrm{X}_{\mathrm{i}}\left|\frac{\mathrm{K}_{\mathrm{i}}}{\mathrm{K}_{\mathrm{io}}}-1\right|
$$

where $\mathrm{K}_{0}$ - the bank capital factor; $\mathrm{X}_{\mathrm{i}}$ - group weights indicators; $\mathrm{K}_{\mathrm{i}}$ - indicators (ratios) of the banking activities; $\mathrm{K}_{\mathrm{io}}$ - the reference values of the corresponding coefficients defined by the limit required ratios established by the CBR, and other coefficients are established by the expert method.

We offer and consider it appropriate to set the weighting limit coefficients by the method of expert estimation, as an expert can determine the effect of different coefficients of each group on an overall assessment of the banking institutions' capital, but to date the weighting value is not set. These values can be changed by the decision of the expert council, automatically using modern technology, which will be dictated and determined by macroeconomic and microeconomic changes, respectively (Posnaya et al., 2019). Based on the description of banking institutions on the criterion of reliability, it is proposed to assess their capital in order to prevent a situation of financial crisis and possible bankruptcy based on the model.

The main baseline data in 01.04.2019 and calculation results are presented in Table 1. The calculations also conventionally accepted that $\mathrm{K}_{8}=20 \%$ (maximum risk per borrower) and $\mathrm{K}_{14}=50 \%$, since at present there is no data concerning these indicators. $\mathrm{K}_{8}$ can be calculated based on already existing CBR methods and $\mathrm{K}_{14}$ indicator, implying $\mathrm{K}_{\mathrm{BIT}}$ coefficient, which reflects the level of modern banking information technology (BIT), this is a foundation for the future.

Table 1. Calculations results for the data as of 1.04.2019*

\begin{tabular}{|l|c|c|c|c|c|c|c|c|c|c|c|c|c|c|c|}
\hline \multicolumn{1}{|c|}{ Bank Name } & $\mathbf{K}_{\mathbf{1}}$ & $\mathbf{K}_{\mathbf{2}}$ & $\mathbf{K}_{\mathbf{3}}$ & $\mathbf{K}_{\mathbf{4}}$ & $\mathbf{K}_{\mathbf{5}}$ & $\mathbf{K}_{\mathbf{6}}$ & $\mathbf{K}_{\mathbf{7}}$ & $\mathbf{K}_{\mathbf{8}}$ & $\mathbf{K}_{\mathbf{9}}$ & $\mathbf{K}_{\mathbf{1 0}}$ & $\mathbf{K}_{\mathbf{1 1}}$ & $\mathbf{K}_{\mathbf{1 2}}$ & $\mathbf{K}_{\mathbf{1 3}}$ & $\mathbf{K}_{\mathbf{1 4}}$ & $\mathbf{K}_{\mathbf{0}}$ \\
\hline Sberbank of Russia & 229 & 247 & 62.8 & 13.6 & 77.3 & 8.5 & 16.3 & 20.0 & 108 & 0.342 & 11.9 & 11.9 & 14.6 & 50.0 & $\mathbf{1 6 . 3}$ \\
\hline VTB Bank & 99 & 171 & 70.1 & 11.1 & 82.1 & 7.5 & 14.5 & 20.0 & 215 & 0,302 & 9.3 & 10.3 & 11.7 & 50.0 & $\mathbf{9 . 9 3}$ \\
\hline Gazprombank & 243 & 175 & 50.1 & 13.4 & 85.1 & 7.0 & 23.1 & 20.0 & 314 & 0.241 & 8.5 & 11.1 & 13.2 & 50.0 & $\mathbf{1 6 . 2}$ \\
\hline Rosselkhozbank & 98 & 158 & 50.8 & 12.8 & 78.2 & 4.3 & 22.4 & 20.0 & 233 & 0.631 & 9.2 & 10.4 & 14.7 & 50.0 & $\mathbf{9 . 5 4}$ \\
\hline Alfa Bank & 133 & 144 & 50.5 & 13.3 & 83.8 & 7.5 & 24.2 & 20.0 & 262 & 0.063 & 10.0 & 12.0 & 13.0 & 50.0 & $\mathbf{1 0 . 0}$ \\
\hline Moscow Credit Bank & 68 & 228 & 23.8 & 12.6 & 83.0 & 18.8 & 22.9 & 20.0 & 227 & 0.69 & 9.2 & 12.5 & 20.5 & 50.0 & $\mathbf{8 . 0 2}$ \\
\hline Bank FC Otkritie & 172 & 329 & 35.4 & 12.2 & 47.7 & 18.0 & 40.2 & 20.0 & 135 & 0,324 & 18.3 & 18.3 & 18.3 & 50.0 & $\mathbf{9 . 5 3}$ \\
\hline UniCredit Bank & 148 & 252 & 47.0 & 15.7 & 78.3 & 1.8 & 17.4 & 20.0 & 179 & 0.155 & 13.6 & 13.6 & 16.5 & 50.0 & $\mathbf{3 1 . 4}$ \\
\hline Raiffeisen Bank & 111 & 161 & 48.3 & 14.6 & 83.2 & 13.9 & 16.0 & 20.0 & 156 & 0.299 & 10.1 & 10.8 & 13.5 & 50.0 & $\mathbf{8 . 6 6}$ \\
\hline Rosbank & 111 & 120 & 50.0 & 14.1 & 83.2 & 6.8 & 24.8 & 20.0 & 145 & 0.051 & 8.4 & 10.0 & 12.5 & 50.0 & $\mathbf{1 . 9 8}$ \\
\hline \multicolumn{1}{|c}{$\mathrm{K}_{\text {io }}, \% \rightarrow$} & 15 & 50 & 120 & 5.00 & 4.00 & 1.00 & 5.00 & 25.0 & 800 & 3.00 & 4.50 & 5.50 & 8.00 & 50.0 & \\
\hline
\end{tabular}

* values of parameters $K_{1}-K_{14}(\%)$ are taken from open source data; bank capital factor $K_{0}$ is a rating integral characteristic (dimensionless). 
Based on the results of the calculations, we can make the following conclusions regarding the probability of bank failures.

Our studies range by a factor of stability of the bank capital is proposed to establish in the range of 10 to 20 units. This would indicate a consistently stable position of banking institutions and according to the parameters of reliability. Schematically this fact is shown in Figure 1.

Figure 1. Bankruptcy risk forecasting factors according to the $K_{0}$ bank capital factor

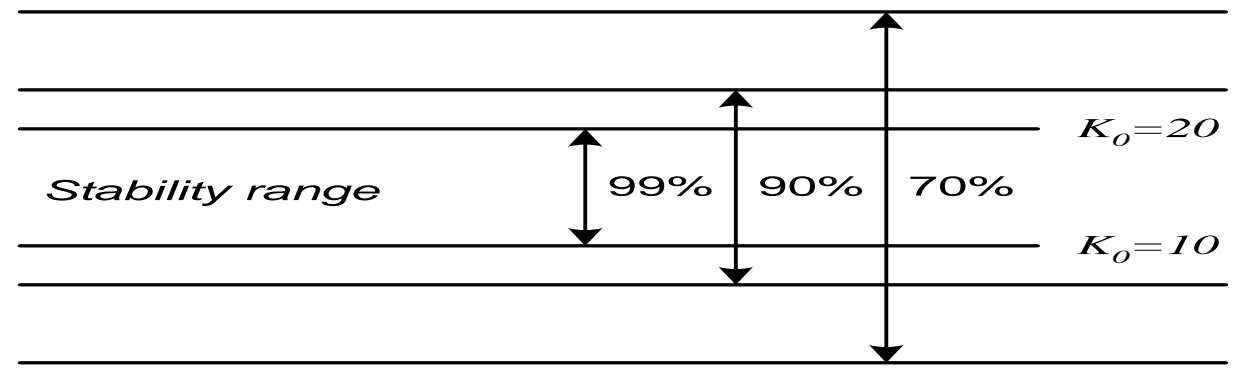

Percentage ranges are set arbitrarily and represent the fact that the stability range from 10 to 20 units can be treated as $99 \%$ stability banking and minimizing the risk of bankruptcy. The banks with capital factor close to the corridor stability demonstrated $90 \%$ level of stability. The remaining banks can be attributed to high-risk banking institutions from the viewpoint of a high probability of failure.

\section{Results}

The result of the calculations is the following. The most stable banking institutions operating on the capital factor and, as a consequence, according to the level of reliability is the Sberbank of Russia PJSC, the leader and the degree of reliability and value of capital factor has the second place as a result of the calculation capital factor of Gazprombank JSC. Its rating level of reliability is the third position, in the position in terms of reliability and capital factor are practically the same; next position - the third factor capital is proved by Alfa-Bank JSC, which occupies the fifth place according to reliability criterion, that practically correlated, and a guarantee of financial stability.

Three banking institutions: VTB Bank (a little less than 10 units, indicating a very high level of financial stability and reliability), then of Rosselkhozbank JSC, which also holds the fourth position of the official statistical reliability, and Bank FC Otkritie PJSC, with its reliability ranked seventh, which also confirms the stability of the financial activity shared fourth position in terms of capital factor.

The fifth place in the capital factor calculation belongs to the Raiffeisen Bank, ranks the ninth on the statistical parameters of reliability. To do this, the bank can assume the 
position of conservative management, the probability of bankruptcy is low, but the policy is quite stable and risk-free, as may indicate the direction of quality of bank management (Grebenik, 2014; Usenko et al., 2018; Hirdinis, 2019).

The UniCredit JSC and Rosbank deviate significantly from the corridor stability range of the indicator values. Very low value of 1.98 can be explained by low adaptive management inert, not considering the ever-changing conditions of the financial situation at the macro and micro levels. As far as the UniCredit Bank JSC, the policy of management of banking institutions can be characterized as aggressive, as evidenced by the largest value of the capital factor equal to 31.4. That is, the bank, with a huge customer base, stable and profit potential is investing the maximum amount of resources to highrisk and highly profitable activities.

These facts cannot be considered as positive because the results of calculations of bank capital held by banking institutions in the Crimea in 2017 (Posnaya et al., 2019), has confirmed the result of the bankruptcy of banks, which have similar financial positions with the UniCredit JSC and Rosbank.

\section{Conclusions and recommendations}

Thus, we can conclude that the reliability data are closely correlated with the values of the factor of bank capital, is an indicator of the level of customer confidence to the banking institution confirmed the minimum probability of bankruptcy of the institution (the characteristics of capital factor, calculated by using a selective model).

Therefore, developed and presented in the study selective evaluation model is proposed to implement the bank capital to check the banking institutions of the Russian Federation, by the regulator in order to identify existing and potential problems affecting the functioning of the commercial banks and the banking system as a whole.

\section{References:}

Bortnikov, G.P. 2007. Economic Capital as a Management Tool. Management in a Credit Institution, 5, 45-52.

Grebenik, T.V. 2014, Modern Features of Effective Quality Management of the Loan Portfolio. Naukovedenie (Internet Journal), Moscow, 5(24), 1-11.

Hirdinis, M. 2019. Capital Structure and Firm Size on Firm Value Moderated by Profitability. International Journal of Economics \& Business Administration, 7(1), 174-191.

International Convergence of Capital Measurement and Capital Standards: A Revised Framework Basel, http://www.bis.org/publ/bcbs /07.htm.

Kryksin, G.V. 2005. Formation of the development strategy of regional banks as a condition for increasing business activity. Thesis, Moscow.

Mahboud, R. 2017. Main Determinants of Financial Reporting Quality in the Lebanese Banking Sector. European Research Studies Journal, 20(4B), 706-726. 
Milenkov, A.V. 2005. Improving the methodology for assessing the stability of the regional banking system. Thesis, Moscow.

Posnaya, E., Semeshina, N., Vorobyova, I., Mohnitskaya, D. 2017. Selective Method of a Bank Capital Assessment in Russian Federation and Other Country in the Context of Globalization. Proceedings of the 17th International Scientific Conference on Globalization and its Socio-Economic Consequences, Rajecke Teplice, Slovakia, (Part 4), 2089-2095.

Posnaya, E.A., Kaznova, M.I., Shapiro, I.E., Vorobyova, I.G. 2018a. Theory and Practice of Capital Estimation Methods: An Application in Bank Management. European Research Studies Journal, 21(S2), 497-505.

Posnaya, E.A., Kolesnikov, A.M., Antokhina, Y.A. 2018b. Application features of capital estimation methods in the bank management system. St. Petersburg State Polytechnical University Journal. Economics, 3, 161-174.

Posnaya, E.A., Semenyuta, O.G., Dobrolezha, E.V., Smolander, M. 2019. Modern Features for Capital Portfolio Monitoring. International Journal of Economics and Business Administration, 7(S1), 53-60.

Raisberg, B.A., Lozovsky, L.Sh., Starodubtseva, E.B. 2005. Modern Economic Dictionary. Moscow, INFRA-M.

Rupeika-Apoga, R., Zaidi, H.S., Thalassinos, E.Y., Thalassinos, I.E. 2018. Bank Stability: The Case of Nordic and Non-Nordic Banks in Latvia. International Journal of Economics and Business Administration, 6(2), 39-55.

Sharifz, K., Mullakhmetov, N.F., Sadriev, D.R., Akhmetshin, M.E. 2018. Corporate Culture in Management Systems. European Research Studies Journal, 21(1), 519528.

Tachmatzidi, I. 2019. Comparative Analysis of Takeover Defenses in Strong and Weak Economies: The Paradigm of the UK and Greece, European Research Studies Journal, 22(2), 254-264.

Usenko, L.N., Bogataya, I.N., Bukhov, N.V., Kuvaldina, T.B., Pavlyuk, A.V. 2018.

Formation of an integrated accounting and analytical management system for value analysis purposes. European Research Studies Journal, 21(S1), 63-71. 